\title{
Rice Yield Estimation using Below Cloud Remote Sensing Images Acquired by Unmanned Airborne Vehicle System
}

\author{
Teoh, C.C ${ }^{\#}$, Mohd Nadzim, N\#, Mohd Shahmihaizan, M.J ${ }^{\#}$, Mohd Khairil Izani, I ${ }^{\#}$, Faizal, K \\ Mohd Shukry, H.B \\ \# Engineering Research Centre, Malaysian Agricultural Research and Development Institute, 50774 Kuala Lumpur, Malaysia \\ E-mail: cchin@mardi.gov.my
}

\begin{abstract}
A method using unmanned airborne vehicle system (UAVS) and image processing technique to enable estimation of rice yield was developed. A digital Tetracam camera was mounted on a CropCam unmanned airborne vehicle (UAV) to acquire red (R), green (G) and near infrared (NIR) images of rice crops at the height of $300 \mathrm{~m}$ above ground. NIR and $R$ values were used to calculate normalised difference vegetation index (NDVI) value. Relationships between yield versus R, G, NIR and NDVI values were analysed. Results showed that the highest relationship was found in NDVI followed by $R$, G and NIR with coefficient of determination ( $r^{2}$ ) values of $0.748,0.727,0.395$ and 0.014 respectively. Therefore, a yield estimation model using NDVI value was developed from the linear regression analysis. The results showed that the model was capable of estimating rice yield with an average accuracy value of 80.3\%.
\end{abstract}

Keywords - Unmanned airborne vehicle system; below cloud remote sensing; normalised difference vegetation index; rice yield estimation; linear regression analysis.

\section{INTRODUCTION}

Rice is a staple food for more than 3 billion people in the world. Currently, the rice self-sufficiency level for Malaysia was $71.4 \%$ [1]. Total area of rice cultivation in Malaysia in 2014 was 689,732 hectares with a total production of about of 2.65 million tonnes [2]. The capability to predict crop yield before harvesting is also an important factor, as it enables farm managers to change farming practices throughout the growing season in order to maximise profit and yield, while minimising costs. It can also be of paramount importance for timely initiating food trade to secure the national demand and timely organise food transport within countries [3].

Various satellites have been successfully launched and remote sensing data has the potential to provide timely, systematic high quality spatial and accurate information about land features including environmental impacts on crop growth [4]. Natural factors such as water availability, soil quality and plant health are important for estimating the predicted yield of a field [5].

Recently, satellite remote sensing technology has been widely used for crop yield prediction. Various satellite derived indices have been used to evaluate crop condition. Some of the indices like normalised difference vegetation index (NDVI) was found to be directly related to crop yield.
This NDVI has been widely used for agricultural cropping and vegetation studies. The NDVI is calculated by:

$$
\mathrm{NDVI}=(\mathrm{NIR}-\mathrm{R}) /(\mathrm{NIR}+\mathrm{R})
$$

where, NIR is radiance value for near-infrared band and R is radiance value for red band [6].

Several methods have been developed to predict crop yields such as generating regression model, to develop direct empirical relationships between the NDVI measurements and crop yield. Many studies that related NDVI measurements to crop yield have been conducted for wheat, maize, rice, millet, sorghum, barley, soybean, ground nut, sugar beet, alfalfa, rye, pea and canola. These methods are used due to many of the conditions that affect crop growth, development and ultimately yield that could be captured through the NDVI [7].

However, the application of satellite-based images are still difficult to monitor the variation in a paddy rice field caused by spectral and temporal resolution as they can be affected by variable weather conditions [8] and low resolution. As mentioned in [9], the low-resolution satellite images are only valuable for large-scale studies and are not suitable for the small-scale farms prevalent in many areas of Asia. They also urged that some satellites providing higher-resolution images have long revisit times and this will limit the utility for any application that might require frequent images to monitor 
crop. To solve the problem, various unmanned low altitude remote sensing (LARS) systems have been developed and used in remote image acquisition for agricultural applications. Some LARS platforms such as kites, balloons, high-clearance tractors and unmanned airplanes and helicopters have been successfully used for agricultural applications in different cropping systems [10].

This paper reports a study of the unmanned airborne vehicle system (UAVS) equipped with a digital Tetracam camera for below cloud cover aerial image acquisition and image processing technique for rice crop yield prediction.

\section{MATERIAL AND METHOD}

Fig. 1 shows the flow of the methodology consisting of field-based data collection, images acquisition, spectral reflectance value extraction, statistical analysis and yield prediction map generation.

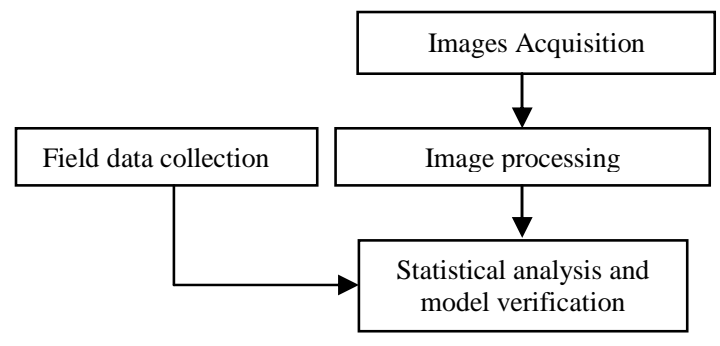

Fig. 1 Methodology flow

\section{A. Field data collection}

An experiment on plant growth was conducted with an application of six different fertilizer treatments in the paddy field at Kampung Setia Jaya, Yan, Kedah. The experiment was carried out by planting variety MR219 seeds in eighteen fertilizer treatment plots with measuring $12 \mathrm{~m} \mathrm{x} 12 \mathrm{~m}$ each. The plots were arranged in a randomised block design for three replications of six $\mathrm{N}$-treatments (i.e. 0, 50, 100, 130, 150 and $170 \mathrm{~kg} / \mathrm{ha}$ ) to obtain a potential wide range of yield. The matured rice crop was harvested from all the sample areas of $5 \mathrm{~m}^{2}$ at the centre of each treatment plot on 9 January 2013. Twenty two farmer plots outside the treatment plots were randomly selected for yield prediction regression model verification purpose. The rice crop at mature stage rice of all the plots were harvested using a combine harvester and rice yields data were recorded at the rice mill.

\section{B. Images acquisition}

A Tetracam digital camera was mounted on a CropCam unmanned airborne vehicle (UAV) (Fig. 2) to acquire near real time red $(\mathrm{R})$, green $(\mathrm{G})$ and near infrared (NIR) images of rice crops at a height of $300 \mathrm{~m}$ above ground on 9 June 2013. The Tetracam digital camera contains a single 3.2 megapixel sensor optimised for capture of visible light wavelengths longer than $520 \mathrm{~nm}$ and near-infrared wavelengths up to $920 \mathrm{~nm}$. The CropCam is a radio controlled model glider plane equipped with a Trimble $1 \mathrm{~Hz}$ update rate, Lassen IQ (P/N 46240-25), a miniature autopilot and digital camera. The weight of the miniature CropCam aircraft is about $2.7 \mathrm{~kg}$, has a $2.44 \mathrm{~m}$ wingspan and an overall length of $1.22 \mathrm{~m}$. The engine runs on four 2,100 mah lithium polymer batteries. A set of full charged batteries provides about $30 \mathrm{~min}$ running time. The average speed of the CropCam is $60 \mathrm{~km} / \mathrm{h}$ and can fly in winds up to $30 \mathrm{~km} / \mathrm{h}$. The CropCam can fly at an altitude of 122 - $640 \mathrm{~m}$ (depending on the country's flying circular or regulation). The MP2028P Autopilot is installed and pre-programmed with a capability to program user flight plans. The Hand-launched CropCam automatically flies from take-off to landing and provides high resolution GPS based images on demand. Both the CropCam and the camera perform automatically to take GPS based digital images.

\section{Image processing}

All captured images with latitude, longitude and altitude information were mosaiced and processed to produce an NDVI image using a commercial PCI image processing software. After processing the image spatial resolution was $12 \mathrm{~cm}$. The locations of yields data taken at each centre of the treatment plot were identified. A 42 x 42 pixels mask equal to an area of $5 \mathrm{~m}^{2}$ square was marked at the centre of each treatment plot on the image. Average R, G, NIR and NDVI values under the mask were calculated by the software.

\section{Statistical analysis}

Relationships between yield and R, G, NIR and NDVI values were analysed to establish the calibration curve to estimate yield. The best coefficient of determination $\left(\mathrm{r}^{2}\right)$ of the calibration curve was selected to estimate yield. The yield prediction regression model was verified by the twenty two farmer plots rice yields data.

\section{RESULTS AND DISCUSSION}

Table 1 illustrates the rice yields with different $\mathrm{N}$ fertilizer applications for three replications. Average rice yield ranged from $0.83 \mathrm{~kg} / \mathrm{m}^{2}$ to $1.01 \mathrm{~kg} / \mathrm{m}^{2}$. Fig. 3 shows the relationship between rice yields and $\mathrm{N}$ fertilizer treatments. Rice yield is closely related to the $\mathrm{N}$ applied in the field. The rice yield increased linearly from $0.83 \mathrm{~kg} / \mathrm{m}^{2}$ to $1.01 \mathrm{~kg} / \mathrm{m}^{2}$ as the amount of $\mathrm{N}$ application increased from $0 \mathrm{~kg} / \mathrm{ha}$ to 150 $\mathrm{kg} / \mathrm{ha}$. This is due to sufficient amounts of available nutrients taken up by the plants to develop a healthy crop. However, the rice yield finally decreased to $0.93 \mathrm{~kg} / \mathrm{m}^{2}$ in spite of the increase in $\mathrm{N}$ application rate. Excessive application of $\mathrm{N}$ fertilization will reduce rice yields and encourages excessive vegetative growth which makes the plant susceptible to insects, pests and diseases. Therefore, an optimum usage rate of $\mathrm{N}$ fertilization is essential in growth and development of rice plants for better yield [11].

TABLE I

RICE YIELDS OF THE DIFFERENT N FERTILIZER APPLICATIONS

\begin{tabular}{|c|c|c|c|c|}
\hline \multirow{2}{*}{$\begin{array}{c}\text { N application } \\
\text { rate (kg/ha) }\end{array}$} & \multicolumn{3}{|c|}{ Rice yield $\left(\mathbf{k g} / \mathbf{m}^{2}\right)$} & \multirow{2}{*}{ Average } \\
\cline { 2 - 4 } & $\begin{array}{c}\text { Replicate } \\
\mathbf{1}\end{array}$ & $\begin{array}{c}\text { Replicate } \\
\mathbf{2}\end{array}$ & $\begin{array}{c}\text { Replicate } \\
\mathbf{3}\end{array}$ & \\
\hline 0 & 0.72 & 0.96 & 0.82 & 0.83 \\
\hline 50 & 0.88 & 0.9 & 0.8 & 0.86 \\
\hline 100 & 0.84 & 0.92 & 1.0 & 0.92 \\
\hline 130 & 1.0 & 1.1 & 0.88 & 0.99 \\
\hline 150 & 1.0 & 1.08 & 0.96 & 1.01 \\
\hline 175 & 0.96 & 0.92 & 0.92 & 0.93 \\
\hline
\end{tabular}


Tetracam digital camera

CropCam UAV

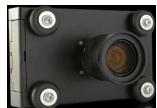

Fig. 2 CropCam UAV and Tetracam digital camera for multispectral image acquisition

Fig. 4a shows the NIR, $\mathrm{R}$ and $\mathrm{G}$ colour composite image after mosaicing of the study area. The NIR (Fig. 4b) and R (Fig. 4c) images were used to produce an NDVI (Fig. 4d) image. It can be seen that variation of colour was found in all the treatment plots with different $\mathrm{N}$ fertilizer application rates. Seven treatment plots were identified where the rice yield ranged from $0.8 \mathrm{~kg} / \mathrm{m}^{2}$ to $1.1 \mathrm{~kg} / \mathrm{m}^{2}$ which were close to the average rice yield with different $\mathrm{N}$ fertilizer applications for three replications. Table 2 shows the rice yields and average $R, G, N I R$, NDVI values under the mask of the centre of each selected treatment plot. $\mathrm{R}$ values are the lowest (25.11 to 31.75) due to the healthy green leaves absorbing radiant energy very efficiently for photosynthesis. The $G$ values show second lowest values (64.49 to 70.25 ) because of the lower absorption by leaves that caused healthy green foliage to appear green in colour. The NIR values (129.25 to 139.7) are much higher than $R$ and $G$ values due to the direct sunlight incident on plants and therefore, have the bulk of energy. This massive amount of energy will result in the plants becoming too warm and the proteins would be irreversibly denatured. Hence, the plants simply reflect it or transmit it through to underlying leaves or to the ground [12]. The NDVI value ranged from 0.61 to 0.67 . Generally, the NDVI values are always between -1 and +1 , where higher values represent more vigorous and healthy vegetation [13].

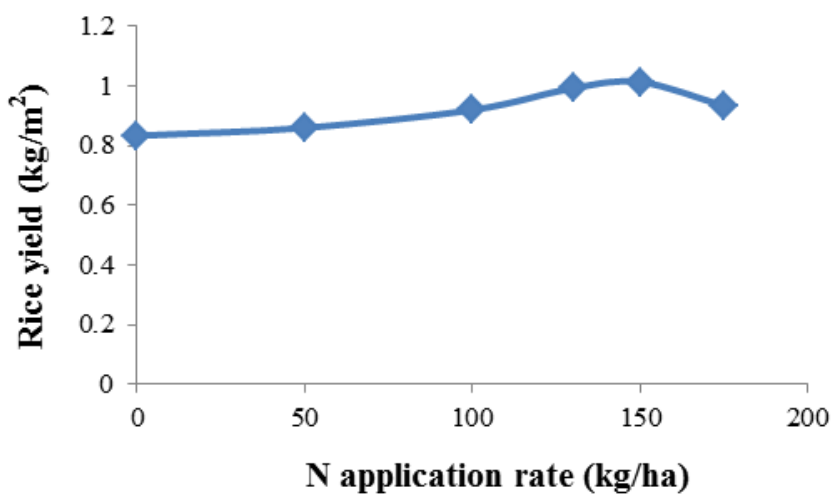

Fig. 3 Relationship between rice yields and $\mathrm{N}$ fertilizer applications

Fig. 5a and $5 \mathrm{~b}$ indicate the relationship between rice yields and R, G, NIR, NDVI values. Results showed that the highest value was found in NDVI $\left(r^{2}=0.75\right)$ followed by $R$ $\left(r^{2}=0.73\right), G\left(r^{2}=0.39\right)$ and NIR $\left(r^{2}=0.01\right)$. Hence, the NDVI value was selected to estimate rice yield. The regression model describing the dependency between rice yield and NDVI value is shown in the equation below:

Rice yield $\left(\mathrm{kg} / \mathrm{m}^{2}\right)=3.744 *(\mathrm{NDVI}$ value $)-1.508$

The yield estimation regression model was verified by twenty two random plots yield data that were collected from the outside treatment plots. Table 3 shows the rice yields obtained from the farmer plots and estimated rice yield using the yield estimation regression model. Comparison results showed that the NDVI value is capable of estimating rice yield with an accuracy of $62.3 \%$ to $98.9 \%$ and the overall average accuracy was $80.3 \%$.

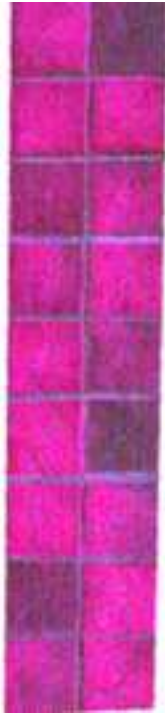

(a)

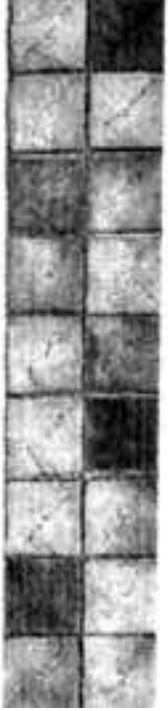

(b)

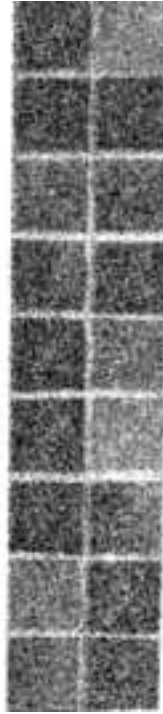

(c)

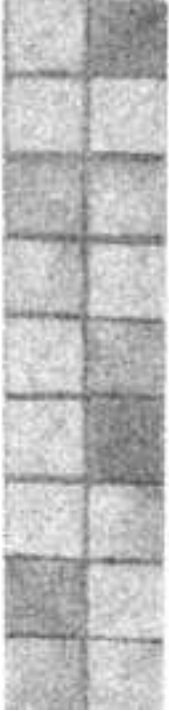

(d)
Fig. 4. (a) NIR, R and G colour composite image, (b) NIR image, (c) R image and (d) NDVI image

TABLE II

Rice YiELDS AND AVERAGE R, G, NiR, NDVI VALUES

\begin{tabular}{|c|c|c|c|c|}
\hline \multirow{2}{*}{$\begin{array}{c}\text { Rice yield } \\
\left(\mathbf{k g} / \mathbf{m}^{\mathbf{2}}\right)\end{array}$} & \multicolumn{4}{|c|}{ Average values } \\
\cline { 2 - 5 } & $\mathbf{R}$ & $\mathbf{G}$ & $\mathbf{N I R}$ & NDVI \\
\hline 0.80 & 31.04 & 68.33 & 133.57 & 0.62 \\
\hline 0.82 & 31.75 & 68.69 & 132.41 & 0.61 \\
\hline 0.88 & 28.68 & 70.25 & 139.70 & 0.66 \\
\hline 0.92 & 28.22 & 65.92 & 130.57 & 0.64 \\
\hline 0.96 & 27.75 & 67.81 & 137.19 & 0.66 \\
\hline 1.00 & 25.11 & 64.49 & 129.25 & 0.67 \\
\hline 1.10 & 26.81 & 66.29 & 137.19 & 0.67 \\
\hline
\end{tabular}

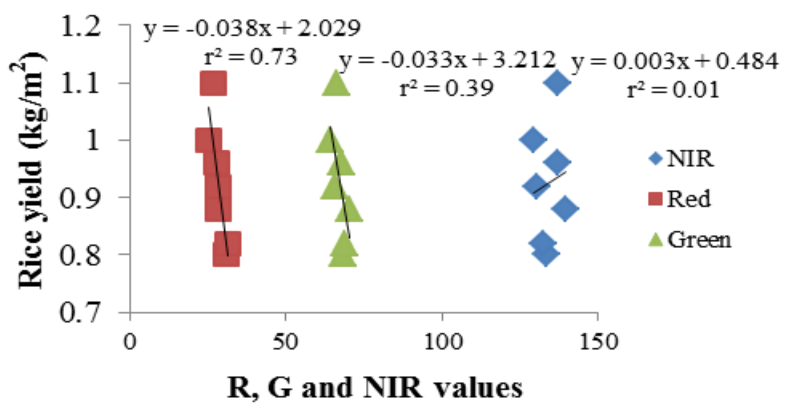

Fig. 5 (a) Relationship between rice yields and R, G and NIR values 


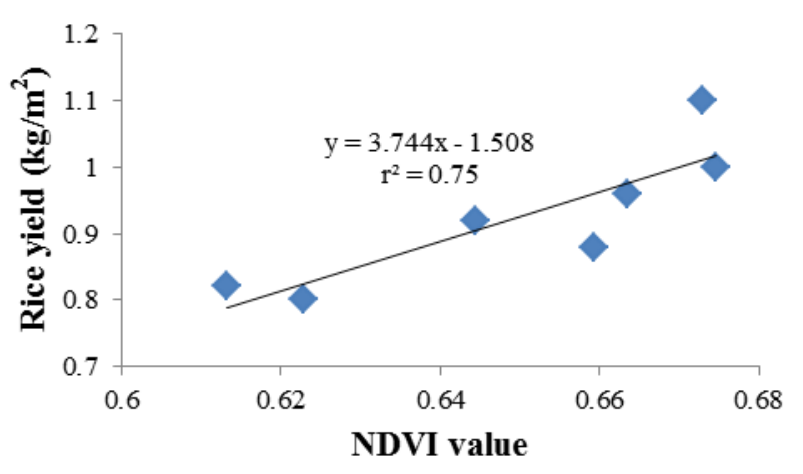

Fig. 5(b) Relationship between rice yields and NDVI values

TABLE III

Rice Yield OBTAINEd From THE FARMERs Plots AND Estimated Rice YIELD USING THE YIELD ESTIMATION REgRESSION MODEL

\begin{tabular}{|c|c|c|}
\hline $\begin{array}{c}\text { Farmer plot yield } \\
(\mathrm{kg})\end{array}$ & $\begin{array}{c}\text { Estimated yield } \\
(\mathrm{kg})\end{array}$ & $\begin{array}{c}\text { Accuracy } \\
(\%)\end{array}$ \\
\hline $9,543.9$ & $12,105.9$ & 73.2 \\
\hline $6,803.4$ & $5,549.04$ & 81.6 \\
\hline $9,187.2$ & $10,750.47$ & 83 \\
\hline $8,274.6$ & $5,910.99$ & 71.4 \\
\hline $8,632.0$ & $10,657.58$ & 76.5 \\
\hline $8,092.5$ & $9,239.3$ & 85.8 \\
\hline $10,126.0$ & $13,054.57$ & 71.1 \\
\hline $8,954.8$ & $10,470.9$ & 83.1 \\
\hline $7,221.0$ & $7,141.89$ & 98.9 \\
\hline $9,421.9$ & $7,653.06$ & 81.2 \\
\hline $9,761.4$ & $11,802.76$ & 79.1 \\
\hline $10,527.0$ & $14,254.97$ & 64.6 \\
\hline $6,796.0$ & $9,137.91$ & 65.5 \\
\hline $9,003.1$ & $9,422.06$ & 95.3 \\
\hline $8,256.3$ & $8,089.02$ & 98 \\
\hline $4,963.4$ & $6,834.39$ & 62.3 \\
\hline $5,109.5$ & $6,437.25$ & 74 \\
\hline $5,017.0$ & $6,158.40$ & 77.2 \\
\hline $5,794.0$ & $7,047.33$ & 78.4 \\
\hline $4,963.4$ & $5,796.93$ & 83.2 \\
\hline $5,709.0$ & $6,412.28$ & 87.7 \\
\hline $5,028.7$ & $5,204.46$ & 96.5 \\
\hline
\end{tabular}

\section{CONCLUSIONS}

An unmanned airborne vehicle system (UAVS) equipped with a digital Tetracam camera has been successfully acquired below cloud cover aerial multispectral images at a height of $300 \mathrm{~m}$ over rice filed. Relationships between rice yields and R, G, NIR and NDVI values have been analysed. The NDVI values and rice yields showed a good correlation with the highest $r^{2}=0.748$. Hence, a yield estimation regression model can be used to predict rice yields based on NDVI values. Verification results showed that the yield estimation regression model using NDVI values was capable of predicting rice yields for twenty two farmer plots with an average accuracy of $80.3 \%$.

\section{REFERENCES}

[1] C. Siwar, N. D. M. Idris, M. Yasar, and G. Morshed. "Issues and challenges facing rice production and food security in the granary areas in the East Coast Economic Region (ECER), Malaysia," Research Journal of Applied Sciences, Engineering and Technology, vol. 7(4), pp. 711-722, 2014.

[2] Agrofood Statistics, Ministry of Agriculture \& Agro-Based Industry Malaysia, 2014.

[3] W.G.M. Bastiaanssen and S. Ali. "A new crop yield forcasting model based on satellite measurements applied across the Indus Basin Pakistan," Agriculture Ecosystem and Environment., vol. 94, pp. 321 $-340,2003$.

[4] W.T. Liu and F. Kogan. "Monitoring Brazilian soybean production using NOAA/AVHRR based vegetation condition indices," International Journal of Remote Sensing., vol. 23(6), pp. 1161 - 1179, 2002 .

[5] J. Bendig, A. Bolten, S. Bennertz, J. Broscheit, S. Eichfuss, and G. Bareth. "Estimating biomass of barley using crop surface models (CSMs) derived from UAV-based RGB imaging," Remote Sens., vol. 6(11), pp. 10395 - 10412, 2014.

[6] J.W. Rouse, R.H. Haas, J.A. Shell, and D.W. Deering, "Monitoring vegetation systems in the Great Plains with ERTS-1," in Proc. 3rd Earth Resources Technology Satellite Symp, 1973, vol. 1, pp. 309 317.

[7] J.Huang, X. Wang, X. Li, H. Tian, and Z. Pan. (2013). Remotely Sensed Rice Yield Prediction Using Multi-Temporal NDVI Data Derived from NOAA's-AVHRR. Plos One 8(8): e70816. doi:10.1371/journal. pone.0070816.

[8] J.V. Stafford. "Implementing precision agriculture in the 21st century.," J. Agric. Eng. Res., vol. 76(3), pp 267 - 275, 2000.

[9] D.W. Lamb and R.B. Brown. "Remote sensing and mapping of weeds in crops," J. Agric. Eng. Res, vol. 78(2, pp 117 - 125, 2001.

[10] K. C. Swain and Q.U. Zamar. (2012). Rice Crop Monitoring with Unmanned Helicopter Remote Sensing Images, Remote Sensing of Biomass - Principles and Applications. (Dr. Lola Fatoyinbo, ed.), ISBN: 978-953-51-0313-4, InTech, DOI: 10.5772/18004.

[11] M.S. Islam, M. Hasanuzzaman, and M. Rokonuzzaman. "Effect of split application of nitrogen fertilizer on morphophysiological parameters of rice genotypes," International Journal of Plant Production., vol. 3(1), pp 51 - 61, 2009.

[12] J.R. Jensen, Introductory Digital Image Processing: A Remote Sensing Perspective. 3rd ed., Upper Saddle River, New Jersey: Prentice Hall, 2005.

[13] M. El-Gammal, R. Ali, and R. Abou Samra. "NDVI Threshold Classification for Detecting Vegetation Cover in Damietta Governorate, Egypt," Journal of American Science., vol 10(8), pp $108-113,2014$. 